\title{
The effects of pumpkin rootstock on photosynthesis, fruit mass, and sucrose content of different ploidy watermelon (Citrullus lanatus)
}

\author{
P.M. YANG ${ }^{*,+}$, S.T. HE ${ }^{* * * *}$, L.N. JIANG*, X.J. CHEN*, Y.F. LI, and J.G. ZHOU* \\ Henan Institute of Science and Technology, 453003 Xinxiang, China* \\ Sumy National Agrarian University, 40021 Sumy, Ukraine**
}

\begin{abstract}
Pumpkin rootstock affects watermelon scion growth, fruit yield, and quality, but the mechanisms of related key enzymes and photosynthesis remain unclear. In this study, net photosynthetic rate $\left(P_{\mathrm{N}}\right)$, chlorophyll $(\mathrm{Chl})$ fluorescence parameters, fruit mass and sugar accumulation, and related key enzyme activities were determined during the fruit development stage in diploid and triploid watermelon lines and corresponding pumpkin rootstock-grafted lines. The results showed that pumpkin rootstock increased $P_{\mathrm{N}}$ and $\mathrm{Chl}$ fluorescence parameters of diploid and triploid watermelon, indicating that pumpkin rootstock could increase photosynthesis, the utilization efficiency of light energy of diploid and triploid watermelon lines. Pumpkin-grafted lines had higher alkaline $\alpha$-galactosidase activity and lower activities of insoluble acid invertase, sucrose phosphate synthase, and sucrose synthase than corresponding own-root lines in diploid and triploid watermelon. It indicates that pumpkin rootstock could increase the unloading of photoassimilates and reduce the conversion of photoassimilates into sucrose in diploid and triploid watermelon fruits.
\end{abstract}

Keywords: graft; photoassimilate; quality; triploid; yield.

\section{Introduction}

Watermelon [Citrullus lanatus (Thunb.) Matsum. \& Nakai] is an important crop because of its sweetness, flavor, high vitamin and nutrient content (Garster 1997, Compton et al. 2004). Most watermelon cultivars are diploid and produce fruit that has red flesh with small black seeds at maturity. However, triploid cultivars have been available for over 60 years and are becoming more prevalent (Kihara 1951). Triploid cultivars are preferred by most consumers because of their sweeter taste and lack of hard seeds (Marr and Gast 1991). For this reason, the use of triploid cultivars has increased markedly, and they represent a significant proportion $(50 \%)$ of the total watermelon production (Maroto et al. 2005). Watermelon often suffers from soilborne pathogens. The lack of resistance to soil-borne pathogens in modern watermelon cultivars is the result of cultivation and selection that have focused on desirable fruit qualities at the expense of disease resistance. A large portion of disease resistance genes has been lost during watermelon domestication (Guo et al. 2012, Lin et al. 2013). One way to reduce losses in the watermelon performance caused by soil-borne pathogens in plants would be grafting watermelon onto rootstocks with high resistance to soil-borne pathogens, e.g., pumpkin and gourd. To date, grafts have been used to suppress damages from soil-borne pathogens (Davis et al. 2008) and increase the tolerance to temperature change and salt stress, enhance nutrient uptake (Huang et al. 2016a), improve water-use efficiency, reduce organic pollutant uptake, limit the toxicity of boron, copper, and cadmium (Colla et al. 2010). Grafting of watermelon has developed very quickly in the last 50 years; in the past, pumpkin rootstock grafting was widely used in watermelon to limit the effects of soil-borne pathogens (Albacete et al. 2015, Shireen et al. 2020). In China, $\sim 20 \%$ of the watermelon crop has been grafted to avoid soil-borne diseases, and it has been a routine technique in continuous cropping systems in many countries (Davis et al. 2008).

Yield and quality are the main selection traits of crops. Sweetness is a key attribute that determines the fruit quality of watermelon. Sucrose, glucose, and fructose are the main sugars that accumulate in watermelon. Sucrose content increases rapidly during fruit development, while fructose and glucose contents are almost constant during watermelon fruit development (Elmstrom and Davis 1981, Brown and Summers 1985, Kano 1991). Therefore, the sugar content of watermelon fruit is mainly determined by the sucrose content. Recent work showed that multiple factors contribute to the formation of fruit mass and sucrose, including photosynthesis, key enzyme activities relevant to fruit mass accumulation, and sugar

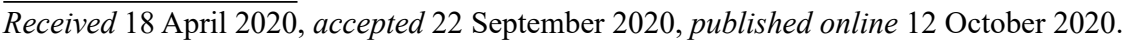

+Corresponding author; phone: +86-373-3040384, e-mail: yangpengming@126.com

Abbreviations: Chl - chlorophyll; DAP - days after pollination; ETR - electron transport rate; $\mathrm{F}_{\mathrm{v}} / \mathrm{F}_{\mathrm{m}}-$ maximum photochemical efficiency of PSII; IAI - insoluble acid invertase; $P_{\mathrm{N}}-$ net photosynthetic rate; SPS - sucrose phosphate synthase; SuSy - sucrose synthase; $\Phi_{\text {PSII }}$ - actual photochemical efficiency of PSII.

Acknowledgments: This study was funded by the Henan Institute of Science and Technology (20703028).

Conflict of interest: The authors declare that they have no conflict of interest. 
synthesis (Liu et al. 2013, Huang et al. 2016a,b). Alkaline $\alpha$-galactosidase (EC 3.2.1.22), insoluble acid invertase (IAI, EC 3.2.1.26), sucrose synthase (SuSy, EC 2.4.1.13), and sucrose phosphate synthase (SPS, EC 2.4.1.14) are the key enzymes involved in fruit mass accumulation and sugar synthesis in watermelon fruit, to a great extent, determining the fruit yield and sugar content of fruit (Liu et al. 2013).

Pumpkin rootstock is reported to increase the fruit mass of watermelon and decrease the sugar content of watermelon fruit (Huang et al. 2016a). But until now, no comprehensive data are available on the relationship between pumpkin rootstock and watermelon photosynthesis, key enzyme activities relevant to fruit mass accumulation and sugar synthesis. Therefore, this work aims to investigate how pumpkin rootstock induces changes in fruit mass and sugar content of diploid and triploid watermelon by changing photosynthesis and key enzyme activities relevant to fruit mass accumulation and sugar synthesis.

\section{Materials and methods}

Plant materials: In this experiment, a commercial pumpkin rootstock cultivar 'Baimi112' (Cucurbita maxima, Henan Institute of Science and Technology), commercial triploid watermelon cultivar 'Zhengzhou No. 3 (3X)', and corresponding diploid watermelon line 'Zhengzhou No. 3 (2X)' [Citrullus lanatus (Thunb.) Matsum. and Nakai., Chinese Academy of Agricultural Sciences] were used. The triploid watermelon cultivar 'Zhengzhou No. 3 (3X)' was obtained by crossing diploid 'Zhengzhou No. 3 (2X)' and corresponding autotetraploid 'Zhengzhou No. 3 (4X)' parental lines.

Experimental design: The seeds of pumpkin, diploid and triploid watermelon were surface sterilized with $3 \%(\mathrm{v} / \mathrm{v})$ sodium hypochlorite for $2 \mathrm{~min}$ followed by three washes with sterile deionized water. After germination at $30^{\circ} \mathrm{C}$ for $24 \mathrm{~h}$, the seeds were sown in 50-cell plug trays filled with a mixture $(1: 1: 1)$ of peat, perlite, and vermiculite $(\mathrm{v} / \mathrm{v})$ in the greenhouse at Henan Institute of Science and Technology, with a 14/10-h day/night photoperiod at temperatures ranging between approximately 22 and $30^{\circ} \mathrm{C}$ and ambient relative humidity. For grafting, pumpkin rootstock seedlings need to be larger than the scion seedlings. Therefore, the rootstock seeds of pumpkin were sown $5 \mathrm{~d}$ earlier than that of the watermelon scion (triploid and diploid watermelon) seeds. Two grafting combinations of watermelon lines were used, i.e., triploid watermelon (3X) grafted onto pumpkin (3X/P) and a diploid watermelon (2X) grafted onto pumpkin $(2 \mathrm{X} / \mathrm{P})$. Once the pumpkin rootstock seedling produced the second true leaf, grafting was performed by using the hole-insertion grafting method as described by Hassell et al. (2008). The ungrafted diploid and triploid watermelon lines were used as control. To maintain high humidity, seedlings were covered with a layer of transparent plastic film, and seedlings were placed in the shade for $72 \mathrm{~h}$. The plastic film was removed for a short time during the initial days to control relative humidity, and it was completely removed after $10 \mathrm{~d}$ from grafting. When the third true leaf emerged, the ownroot watermelon and grafted-root watermelon seedlings were transplanted into an open field in Xinxiang, China $\left(35^{\circ} 18^{\prime} \mathrm{N}, 113^{\circ} 52^{\prime} \mathrm{E}\right)$, and grown under the same conditions in early May. Each line comprised of two rows and each row included ten individuals. The spacing between the rows was $180 \mathrm{~cm}$, and the spacing between individuals in a row was $50 \mathrm{~cm}$. The treatment was replicated four times and was arranged in a randomized complete block design. The flowers were hand-pollinated and tagged. Five individual fruits were chosen randomly from each line of each treatment at 10,20,30 d, respectively, after pollination and used for testing fruit mass, dry matter content (whole fruit), sugar content (flesh), and assaying enzyme activity (flesh). The flesh (central portion) samples were collected and divided into two subsets. One subset was freezedried to a powder for sugar content determinations. The other subset was immediately frozen in liquid nitrogen and stored at $-80^{\circ} \mathrm{C}$ for the enzyme assays. Each point, therefore, represents the average of five samples from individual fruit.

The net photosynthetic rate $\left(\boldsymbol{P}_{\mathrm{N}}\right)$ was measured under the conditions of the natural environment (field). We also recorded the PFD and temperature at the experimental location at this time (Fig. 1). LI-6400 portable photosynthesis system (LI-COR Co., USA) was used to measure the $P_{\mathrm{N}}$ of the third leaf (from the top) at 10,20,30 d, respectively, after pollination under natural conditions. They were measured every hour from 8:00-18:00 h. Each result shown was the mean of ten replicated treatments.

The Chl fluorescence parameters of the third leaf were measured with a portable Chl fluorometer (Mini-PAM, Heinz Walz GmbH, Effeltrich, Germany). The mean values of leaf electron transport rate (ETR), maximum photochemical efficiency of PSII $\left(\mathrm{F}_{\mathrm{v}} / \mathrm{F}_{\mathrm{m}}\right)$, and actual photochemical efficiency of PSII $\left(\Phi_{\mathrm{PSII}}\right)$ were measured as described by Baker (2008). Each result shown was the mean of ten replicated treatments.

Sucrose and total sugar determination: Sucrose and total sugar content was assayed as described by Liu et al. (2013). Approximately $200 \mathrm{mg}$ of freeze-dried flesh per sample was ground to a fine powder and extracted for $1 \mathrm{~h}$ in $10 \mathrm{~mL}$ of $50 \%$ ethanol at $80^{\circ} \mathrm{C}$ and then centrifuged at $3,000 \times g$ for $10 \mathrm{~min}$. The pellet was again extracted and centrifuged, and the combined supernatants were placed in a volumetric flask $(25 \mathrm{~mL}) ; 2 \mathrm{~mL}$ of the sample was centrifuged at $3,000 \times g$ for $10 \mathrm{~min}$. The supernatants $(1 \mathrm{~mL})$ were filtered through a $0.45-\mu \mathrm{m}$ HPLC nylon filter (Membrana, Germany). The sugars in the sample were separated in an analytical HPLC system (Pump System LC-10ATVP, Shimadzu, Japan) fitted with a Shodex Asahipak NH2P-504E column $(4.6 \times 250 \mathrm{~mm}$; Shodex, Japan) using a refractive index detector (RID-10A, Shimadzu, Japan). Each result shown was the mean of five replicated treatments. 


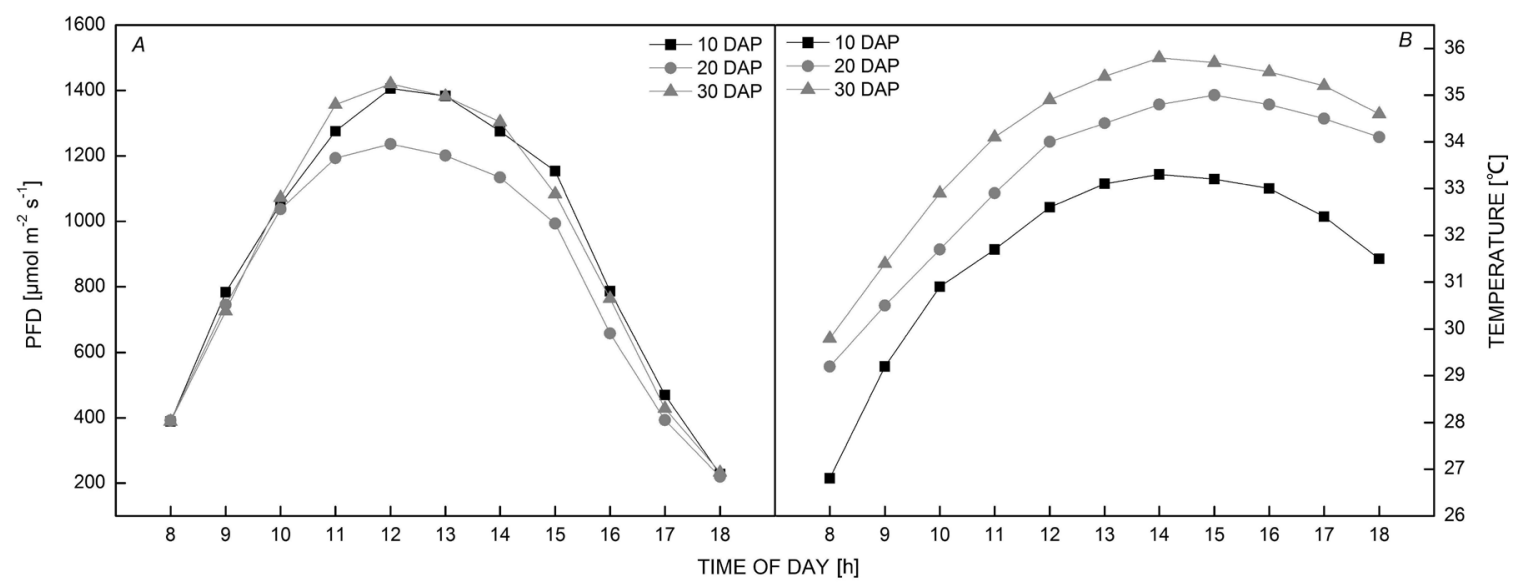

Fig. 1. Diurnal changes of light intensity $(A)$ and temperature $(B)$ at $10,20,30 \mathrm{~d}$ after pollination. DAP - days after pollination.

Extraction and assay of alkaline $\alpha$-galactosidase: The alkaline $\alpha$-galactosidase activity was assayed according to the method of Gao and Schaffer (1999), with some modifications. Approximately $1 \mathrm{~g}$ of freshly frozen flesh was homogenized in a mortar with four volumes of extraction buffer containing $50 \mathrm{mM}$ Hepes- $\mathrm{NaOH}(\mathrm{pH}$ 7.5), $2 \mathrm{mM}$ EDTA, and $5 \mathrm{mM}$ DTT. All samples were centrifuged at $18,000 \times g$ for $20 \mathrm{~min}$ at $4^{\circ} \mathrm{C}$ to separate the supernatants. After centrifugation, the supernatants were collected for alkaline $\alpha$-galactosidase analysis using $p$-nitrophenyl- $\alpha$-D-galacopyranoside (pNPG) as a substrate. The initial reaction buffer contained $5 \mathrm{mM}$ pNPG in $50 \mathrm{mM}$ Hepes buffer $(\mathrm{pH} 7.5)$. The samples were incubated at $37^{\circ} \mathrm{C}$. The reaction was terminated after $10 \mathrm{~min}$ by adding four volumes of $0.2 \mathrm{M} \mathrm{Na}_{2} \mathrm{CO}_{3}$. The release of $p$-nitrophenol was measured spectrophotometrically at $410 \mathrm{~nm}\left(\varepsilon=2.51 \times 10^{4}\right)(S 22 P C$, Shanghai Optical Instrument Factory, China), and p-nitrophenol (Sigma) was used as a standard. Each result shown was the mean of three replicated treatments.

Insoluble acid invertase (IAI) extraction and assay: Insoluble acid invertase activity was measured according to the method of Miron and Schaffer (1991), with some modifications. Approximately $1 \mathrm{~g}$ of freshly frozen flesh was homogenized in a mortar with three volumes of extraction buffer containing $50 \mathrm{mM}$ Hepes- $\mathrm{NaOH}$ (pH 7.5), $0.5 \mathrm{mM}$ Na-EDTA, $2.5 \mathrm{mM}$ DTT, $3 \mathrm{mM}$ diethyldithiocarbamic acid, $0.5 \%(\mathrm{w} / \mathrm{v}) \mathrm{BSA}$, and $1 \%$ $(\mathrm{w} / \mathrm{v})$ insoluble polyvinylpyrrolidone (PVP). All samples were centrifuged at $18,000 \times g$ for $30 \mathrm{~min}$ at $4^{\circ} \mathrm{C}$ to collect the insoluble pellet (containing crude insoluble acid invertases) by separation. The insoluble pellet was homogenized in the extraction buffer, centrifuged, and suspended in $3 \mathrm{~mL}$ of $50 \mathrm{mM}$ Hepes- $\mathrm{NaOH}(\mathrm{pH} 7.5)$ and $0.5 \mathrm{mM}$ Na-EDTA. To solubilize the 'insoluble' acid invertase enzyme, $\mathrm{NaCl}$ ( $0.5 \mathrm{M}$ final concentration) was added to the initial extraction buffer before extraction. All samples were incubated at $4^{\circ} \mathrm{C}$ for $10 \mathrm{~min}$ and centrifuged at $18,000 \times \mathrm{g}$ for $20 \mathrm{~min}$ at $4^{\circ} \mathrm{C}$. The supernatants were collected for analysis of crude insoluble acid invertase activity. Insoluble acid invertase activity was assayed in
$0.8 \mathrm{~mL}$ of $0.1 \mathrm{M} \mathrm{K}_{2} \mathrm{HPO}_{4}-0.1 \mathrm{M}$ citrate buffer ( $\mathrm{pH} 5.0$ ), $0.2 \mathrm{~mL} 0.1 \mathrm{M}$ sucrose, and $0.2 \mathrm{~mL}$ of enzyme extract (for the control). All samples were incubated for $30 \mathrm{~min}$ at $37^{\circ} \mathrm{C}$, after which the reactions were stopped at $100^{\circ} \mathrm{C}$ for $5 \mathrm{~min}$. The content of reducing sugar produced during the reactions of insoluble acid invertase was determined using a 3,5-dinitrosalicylic acid (DNS) color reagent with a spectrophotometer at $540 \mathrm{~nm}\left(\varepsilon=1.31 \times 10^{4}\right)$. The enzyme was added to one sample after the 30 -min incubation for the blank control. Insoluble acid invertase activity in the fruit was calculated as the quantity of reducing sugars produced per min at $37^{\circ} \mathrm{C}$. Each result shown was the mean of three replicated treatments.

Extraction and assay of SuSy and SPS: SuSy and SPS were extracted according to the methods of Hubbard et al. (1989) and Lowell et al. (1989), with some modifications. Frozen flesh was homogenized in a chilled mortar using a 1:5 tissue-to-buffer ratio. The buffer contained $100 \mathrm{mM}$ phosphate buffer ( $\mathrm{pH} 7.5), 5 \mathrm{mM} \mathrm{MgCl}_{2}, 1 \mathrm{mM}$ EDTA, $2.5 \mathrm{mM}$ DTT, $0.1 \%(\mathrm{v} / \mathrm{v})$ Triton $X-100$, and 2\% PVPP $(\mathrm{w} / \mathrm{v})$. The homogenates were centrifuged at $10,000 \times g$ for $30 \mathrm{~min}$ at $4^{\circ} \mathrm{C}$. After centrifugation, the supernatants were dialyzed in a $15-\mathrm{cm}$ dialysis tube (molecular weight cut-off of 8,000-15,000) for approximately $16 \mathrm{~h}$ at $4^{\circ} \mathrm{C}$ against a solution containing $10 \mathrm{mM}$ phosphate buffer (pH 7.5), $0.5 \mathrm{mM} \mathrm{MgCl}, 0.1 \mathrm{~mm}$ EDTA, $0.25 \mathrm{mM}$ DTT, and $0.01 \%(\mathrm{v} / \mathrm{v})$ Triton $X-100$. The solution remaining in the dialysis tube was collected for analysis of crude SuSy and SPS activity. SPS activity was assayed by adding $0.1 \mathrm{~mL}$ of crude extract to $50 \mu \mathrm{L}$ Hepes buffer [50 mM Hepes-NaOH (pH 7.5), $15 \mathrm{mM} \mathrm{MgCl}, 15 \mathrm{mM}$ fructose-6-PNa, $15 \mathrm{mM}$ glucose-6- $\mathrm{PNa}_{2}$, and $15 \mathrm{mM}$ UDP-glucose]. The samples were incubated for $30 \mathrm{~min}$ at $37^{\circ} \mathrm{C}$, after which the reaction was stopped by the addition of $0.2 \mathrm{~mL}$ of $30 \%(\mathrm{v} / \mathrm{v}) \mathrm{KOH}$. The tubes were placed in boiling water for $10 \mathrm{~min}$ to destroy any nonreacted fructose or fructose-6-P. After cooling, $3 \mathrm{ml}$ of a mixture of $0.14 \%(\mathrm{w} / \mathrm{v})$ anthrone in $13.8 \mathrm{M} \mathrm{H}_{2} \mathrm{SO}_{4}$ was added to each sample, and the samples were incubated in a $40^{\circ} \mathrm{C}$-water bath for $20 \mathrm{~min}$. After adding four volumes of $0.14 \%(\mathrm{w} / \mathrm{v})$ anthrone reagent (in $14.6 \mathrm{M} \mathrm{H}_{2} \mathrm{SO}_{4}$ ), absorbance was 
measured at $620 \mathrm{~nm}\left(\varepsilon=1.96 \times 10^{4}\right)$. The procedure for the SuSy assay (measured in the sucrose synthesis direction) was identical to that of SPS except that the reaction mixtures contained $0.1 \mathrm{M}$ phosphate buffer $(\mathrm{pH} 8.0)$ and $60 \mathrm{mM}$ fructose and did not contain fructose-6-P or glucose-6-P. Each result shown was the mean of three replicated treatments.

Statistical analysis: All the data in the present study were expressed as means \pm SE. Significance analysis was performed using $S A S$ software (SAS Institute, Inc., Cary, NC, USA). One-way analysis of variance (ANOVA) method (Tukey's multiple range test) was used to detect the significance $(P<0.05)$.

\section{Results}

$\boldsymbol{P}_{\mathrm{N}}$ : The $P_{\mathrm{N}}$ of the grafted-root line was higher than that of the corresponding own-root line during the fruit development stage, and the difference between the graftedroot line and corresponding own-root line increased with the prolongation of fruit development time in both diploid and triploid watermelon (Fig. 2). These results indicate that pumpkin rootstock could improve photosynthesis of diploid and triploid watermelon.

Chl fluorescence parameters: During the fruit development stage, the $F_{\mathrm{v}} / F_{\mathrm{m}}, \Phi_{\text {PSII }}$, and ETR of the grafted-root line were higher than those of the corresponding ownroot line regardless of diploid watermelon or triploid watermelon (Fig. 3). The $\mathrm{F}_{\mathrm{v}} / \mathrm{F}_{\mathrm{m}}, \Phi_{\text {PSII }}$, and ETR showed significant differences between the grafted-root line and own-root line during the fruit development stage in diploid watermelon (Fig. $3 A, D, E$ ). Meanwhile, the $\mathrm{F}_{\mathrm{v}} / \mathrm{F}_{\mathrm{m}}$, $\Phi_{\text {PSII }}$, and ETR showed significant differences between the grafted-root line and own-root line during the late stage (30 DAP) of fruit development in triploid watermelon (Fig. 3B, $C, F$ ).

The activity of alkaline $\boldsymbol{\alpha}$-galactosidase in fruits decreased with the prolongation of fruit development time for all watermelon lines. However, the alkaline $\alpha$-galactosidase activity of the own-root line decreased sharper than that of the corresponding grafted-root line in both diploid watermelon and triploid watermelon. For diploid watermelon, the alkaline $\alpha$-galactosidase activity in fruits of the grafted-root line was significantly higher than that in fruits of the own-root line during the fruit development stage (Fig. 4A). For triploid watermelon, the activity of alkaline $\alpha$-galactosidase was higher in the grafted-root line than that in the own-root line during the fruit development stage, and the difference of alkaline $\alpha$-galactosidase activity between the grafted-root line and own-root line was significant at the late development stage (30 DAP) (Fig. 4B).

Dry matter and mass accumulation of fruit: The changes in dry matter accumulation were similar to the changes in mass accumulation during fruit development for all watermelon lines (Fig. 5). Single fruit mass and dry matter content increased with the prolongation of fruit development time for all watermelon lines (Fig. 5). For diploid watermelon, the single fruit mass and dry matter content of the grafted-root line were significantly higher than those of the own-root line during fruit development (Fig. 5A,D). For triploid watermelon, the single fruit mass and dry matter content of the grafted-root line were higher than those of the own-root line at various stages of fruit development and the difference was significant during the late stage (30 DAP) of fruit development (Fig. $5 B, C$ ).

The activities of IAI, SPS, and SuSy: For diploid own-root line and corresponding grafted-root line, the IAI activity in flesh first increased sharply and then declined slightly; SuSy activity in flesh first declined slightly and then increased sharply, while SPS activity in flesh was increasing all the time during the fruit development stage (Fig. 6A, D,E). Meanwhile, the activities of IAI, SuSy, and SPS in flesh increased with the prolongation of fruit development time in triploid own-root line and

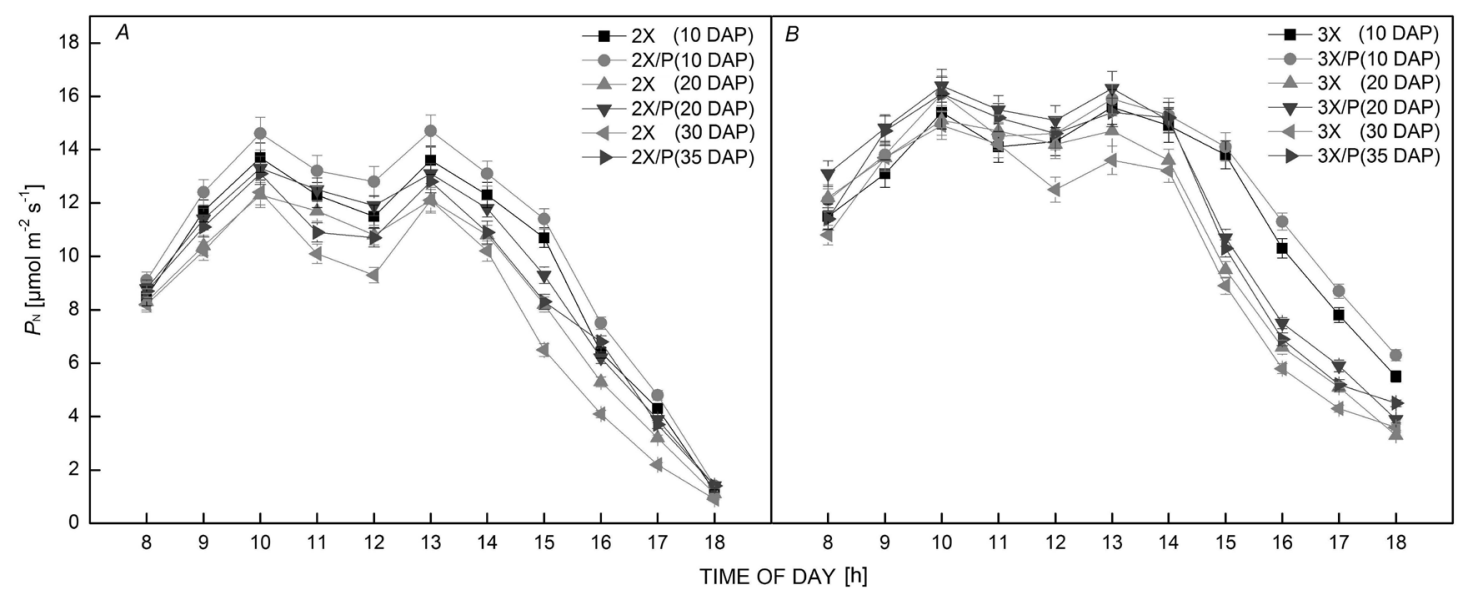

Fig. 2. Changes of net photosynthetic rate $\left(P_{\mathrm{N}}\right)$ in grafted-root watermelon lines and own-root watermelon lines during the fruit development stage. Error bars show SE, $n=10$. DAP - days after pollination, $2 \mathrm{X}$ - diploid watermelon line, $3 \mathrm{X}$ - triploid watermelon line, $2 \mathrm{X} / \mathrm{P}$ - diploid watermelon line grafted onto pumpkin rootstock, $3 \mathrm{X} / \mathrm{P}$ - triploid watermelon line grafted onto pumpkin rootstock. 


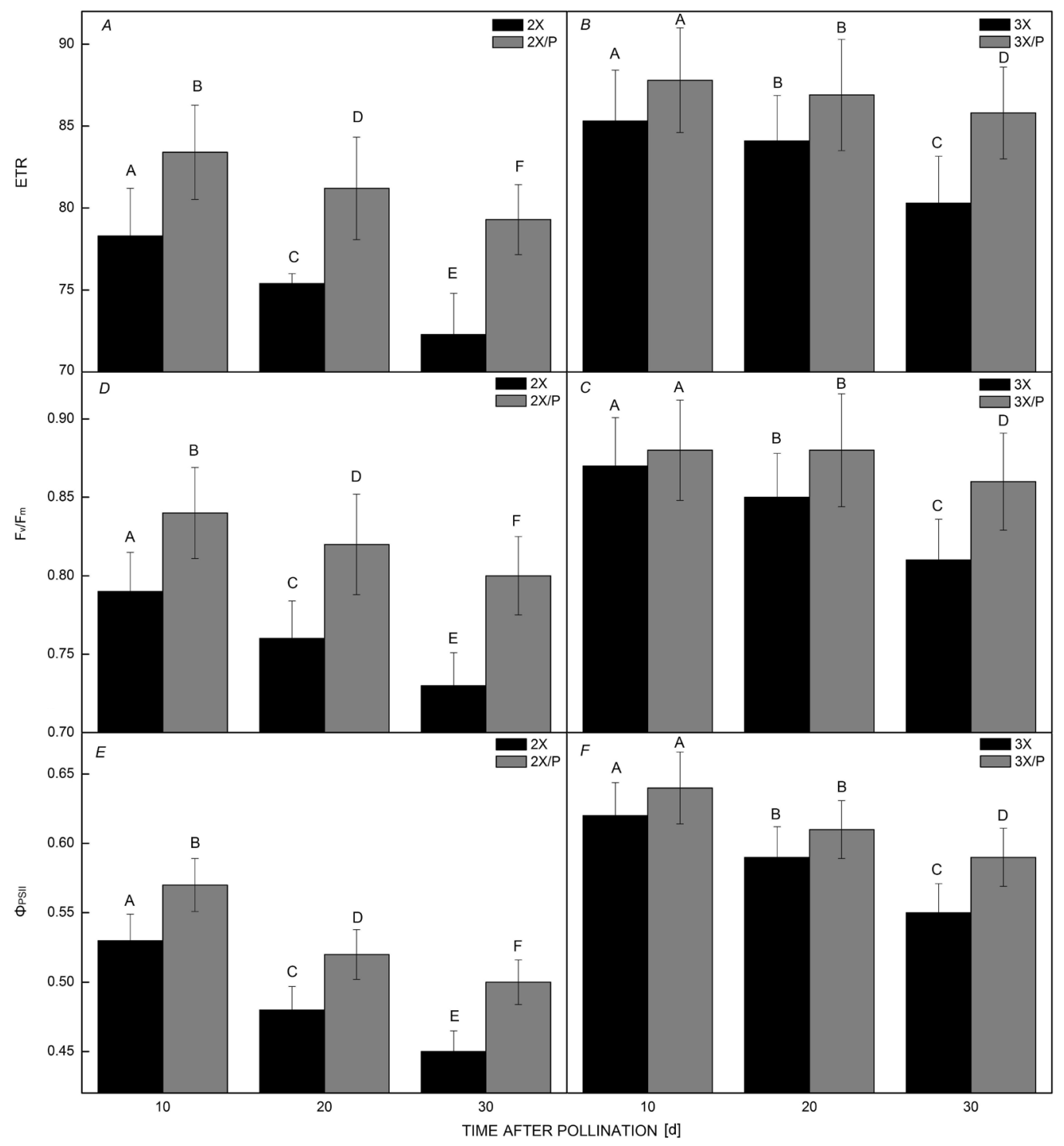

Fig. 3. Changes of chlorophyll fluorescence parameters in grafted-root watermelon lines and own-root watermelon lines during the fruit development stage. Error bars show SE, $n=10$. One-way analysis of variance $(A N O V A)$ was used to identify the difference between the grafted-root watermelon line and the corresponding own-root watermelon line in each treatment. Letters are comparable within graftedroot watermelon line and corresponding own-root watermelon line in each time. Values with different letters are significantly different $(P<0.05)$. DAP - days after pollination, $2 \mathrm{X}$ - diploid watermelon line, $3 \mathrm{X}$ - triploid watermelon line, $2 \mathrm{X} / \mathrm{P}$ - diploid watermelon line grafted onto pumpkin rootstock, $3 \mathrm{X} / \mathrm{P}$ - triploid watermelon line grafted onto pumpkin rootstock, $\mathrm{F}_{\mathrm{v}} / \mathrm{F}_{\mathrm{m}}-$ maximum photochemical efficiency of PSII, $\Phi_{\mathrm{PSII}}$ - actual photochemical efficiency of photosystem, ETR - electron transport rate.

corresponding grafted-root line (Fig. $6 B, C, F$ ). Both diploid watermelon and triploid watermelon, the activities of IAI, SPS, and SuSy were significantly lower in the grafted-root line than those in the corresponding own-root line during the fruit development stage (Fig. 6).

Sucrose and total sugar accumulation: The changes in total sugar accumulation were similar to the changes in sucrose accumulation during fruit development for all watermelon lines (Fig. 7). The contents of sucrose and total sugar in flesh increased with the prolongation of fruit development time for all watermelon lines (Fig. 7). The sucrose and total sugar contents in the flesh of the graftedroot line were significantly lower than those in the flesh of own-root line regardless of diploid or triploid watermelon (Fig. 7).

\section{Discussion}

Mass and sucrose accumulation of crop fruit depends on the capacity of source tissues (especially leaves) to produce photoassimilates, during the fruit development process, as well as on the ability of sink tissues to unload these photoassimilates (Reynolds et al. 2012, Tuncel and Okita 


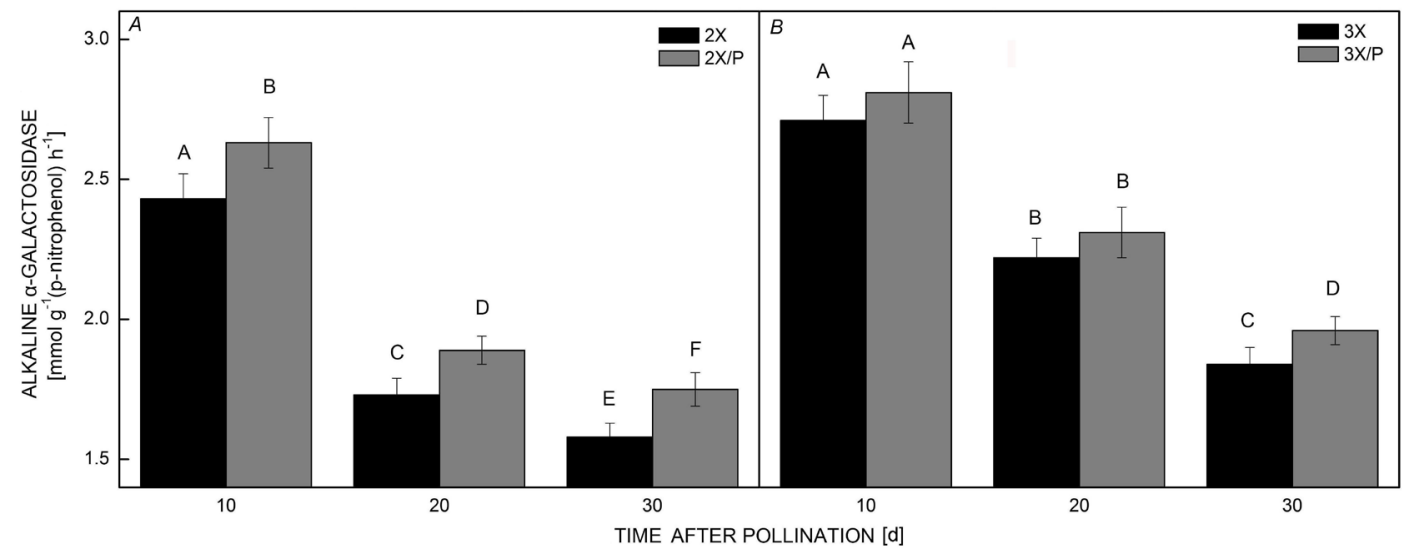

Fig. 4. Alkaline $\alpha$-galactosidase activity in fruits of grafted-root watermelon lines and own-root watermelon lines during the fruit development stage. Error bars show SE, $n=3$. One-way analysis of variance ( $A N O V A)$ was used to identify the difference between the grafted-root watermelon line and the corresponding own-root watermelon line in each treatment. Letters are comparable within graftedroot watermelon line and corresponding own-root watermelon line in each time. Values with different letters are significantly different $(P<0.05)$. DAP - days after pollination, $2 \mathrm{X}$ - diploid watermelon line, $3 \mathrm{X}$ - triploid watermelon line, $2 \mathrm{X} / \mathrm{P}$ - diploid watermelon line grafted onto pumpkin rootstock, $3 \mathrm{X} / \mathrm{P}$ - triploid watermelon line grafted onto pumpkin rootstock.

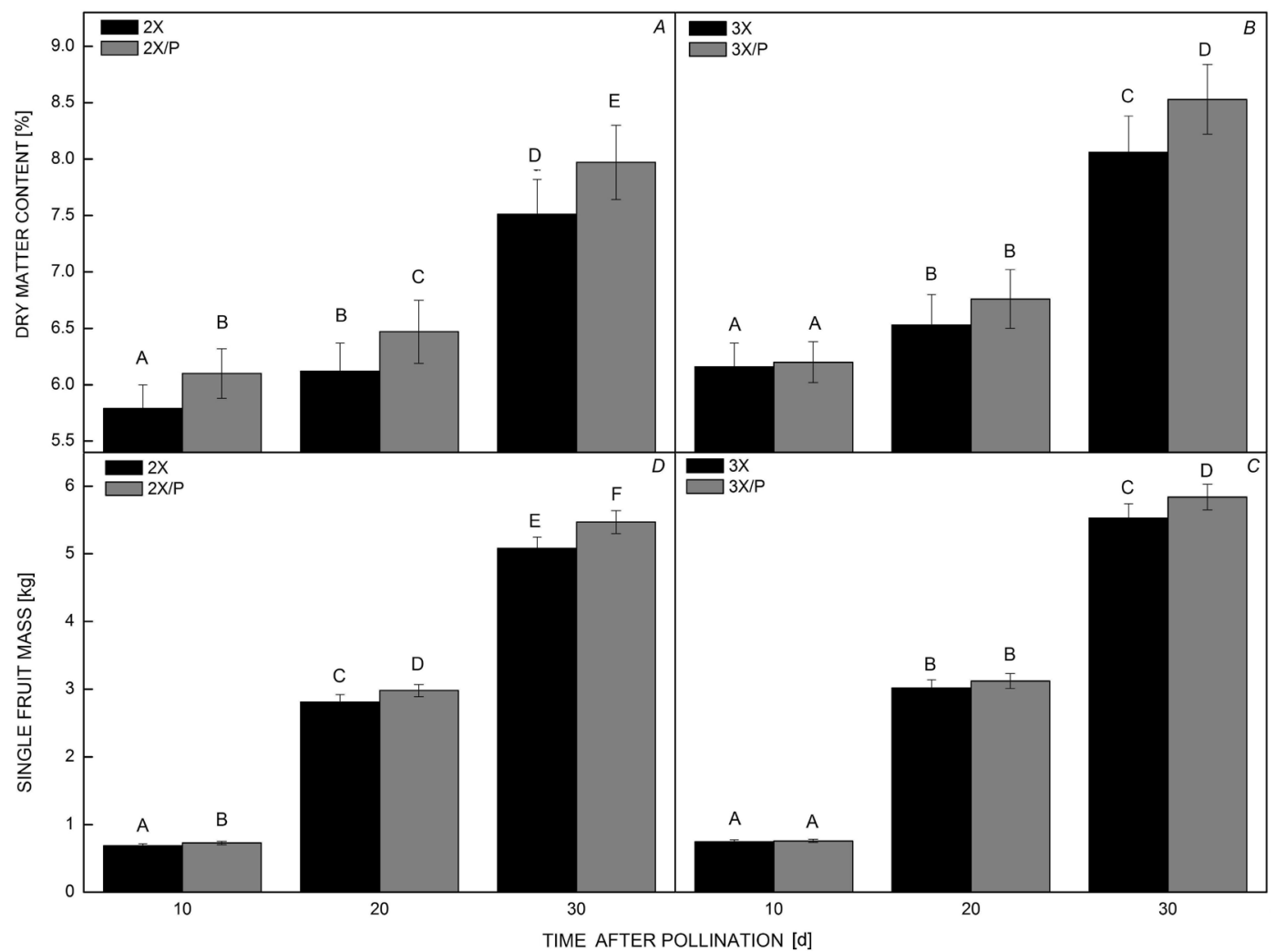

Fig. 5. Fruit mass and dry matter accumulation in grafted-root watermelon lines and own-root watermelon lines during the fruit development stage. Error bars show SE, $n=10$. One-way analysis of variance ( $A N O V A$ ) was used to identify the difference between the grafted-root watermelon line and the corresponding own-root watermelon line in each treatment. Letters are comparable within graftedroot watermelon line and corresponding own-root watermelon line in each time. Values with different letters are significantly different $(P<0.05)$. DAP - days after pollination, $2 \mathrm{X}$ - diploid watermelon line, $3 \mathrm{X}$ - triploid watermelon line, $2 \mathrm{X} / \mathrm{P}$ - diploid watermelon line grafted onto pumpkin rootstock, $3 \mathrm{X} / \mathrm{P}$ - triploid watermelon line grafted onto pumpkin rootstock.

2013). Photosynthesis is the physicochemical process to transduce light energy into chemical energy, and it provides the organic blocks for plant growth and development.
Theoretically, the yield and sugar content of crop fruit can be increased by promoting photosynthesis because photosynthesis is the major metabolic pathway that converts 


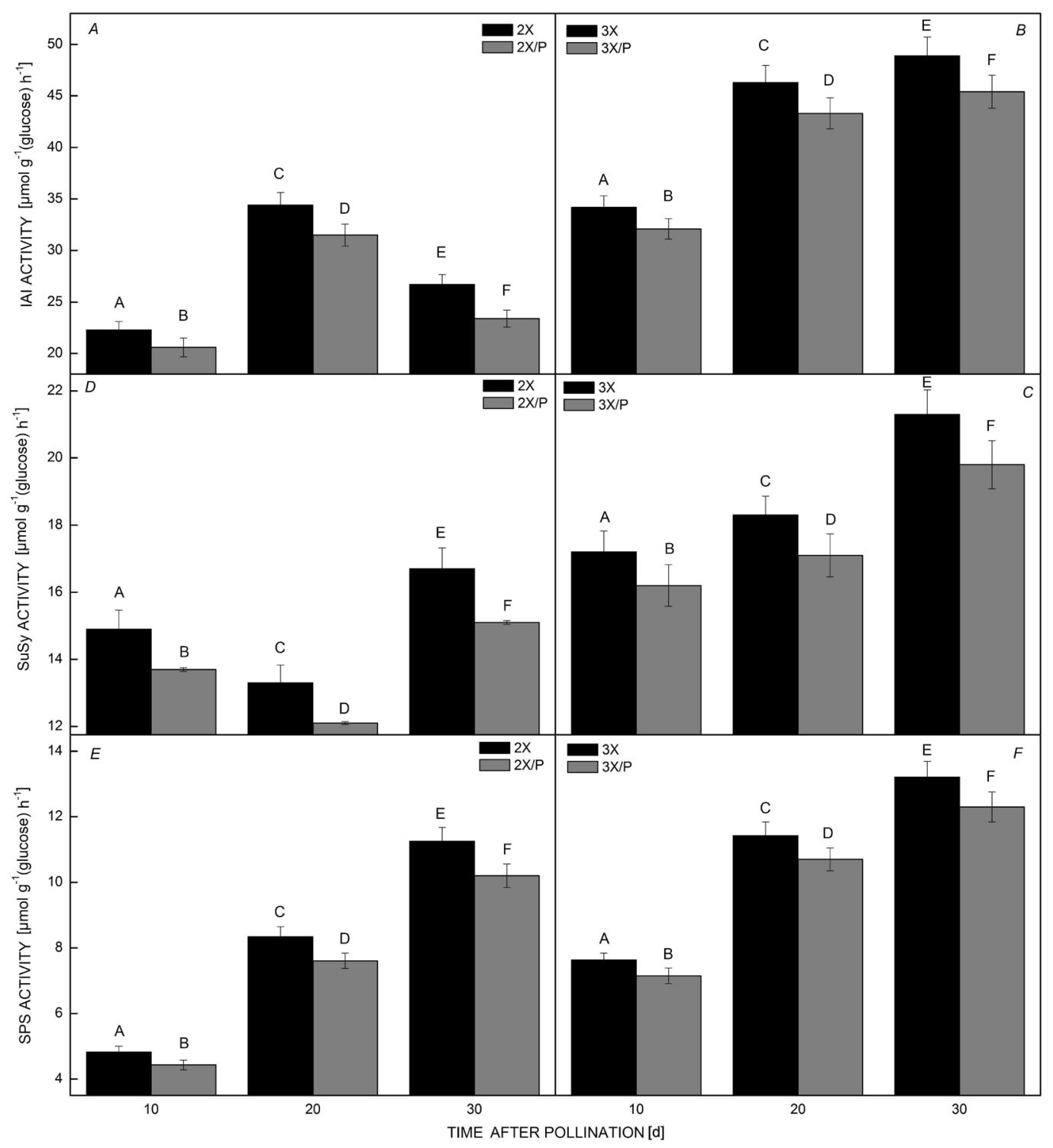

Fig. 6. The activities of insoluble acid invertase (IAI), sucrose phosphate synthase (SPS), and sucrose synthase (SuSy) in the flesh of grafted-root watermelon lines and own-root watermelon lines during the fruit development stage. Error bars show SE, $n=3$. One-way analysis of variance $(A N O V A)$ was used to identify the difference between the grafted-root watermelon line and the corresponding own-root watermelon line in each treatment. Letters are comparable within grafted-root watermelon line and corresponding own-root watermelon line in each time. Values with different letters are significantly different $(P<0.05)$. DAP - days after pollination, $2 X-$ diploid watermelon line, $3 \mathrm{X}$ - triploid watermelon line, $2 \mathrm{X} / \mathrm{P}$ - diploid watermelon line grafted onto pumpkin rootstock, $3 \mathrm{X} / \mathrm{P}$ - triploid watermelon line grafted onto pumpkin rootstock.

carbon dioxide into organic compounds, such as fructose, glucose, sucrose, and starch in plants (Chang et al. 2017). Chl fluorescence provides a measure of the functional status of photosynthesis and has been used as sensitive indicator of plant photosynthetic performance (Naumann et al. 2007, Oukarroum et al. 2009). The increase in $\mathrm{F}_{\mathrm{v}} / \mathrm{F}_{\mathrm{m}}$, $\mathrm{ETR}$, and $\Phi_{\mathrm{PSII}}$ indicates a progressive upregulation in the quantum yield of photosynthesis, rates of carbon fixation, and photosynthetic efficiency (Oxborough 2004, Kalaji et al. 2011, Shu et al. 2013). The $P_{\mathrm{N}}, \mathrm{ETR}, \mathrm{F}_{\mathrm{v}} / \mathrm{F}_{\mathrm{m}}$, and $\Phi_{\text {PSII }}$ were higher in the rootstock-grafted line than that in corresponding own-root line during the fruit development stage in both diploid watermelon and triploid watermelon (Figs. 2,3). These results suggest that pumpkin rootstock could improve photosynthetic capacity and efficiency of light energy utilization, which could improve the capacity of leaves to produce photoassimilates in rootstockgrafted watermelon lines. Various pumpkin rootstocks are more vigorous than cultivated watermelon varieties and responsible for the uptake of mineral nutrients and water in grafted plants (Petropoulos et al. 2012). Pumpkingrafted watermelon plants have higher root volume, root surface area, and number of root tips and forks than corresponding own-root watermelon plants (Huang et al. 


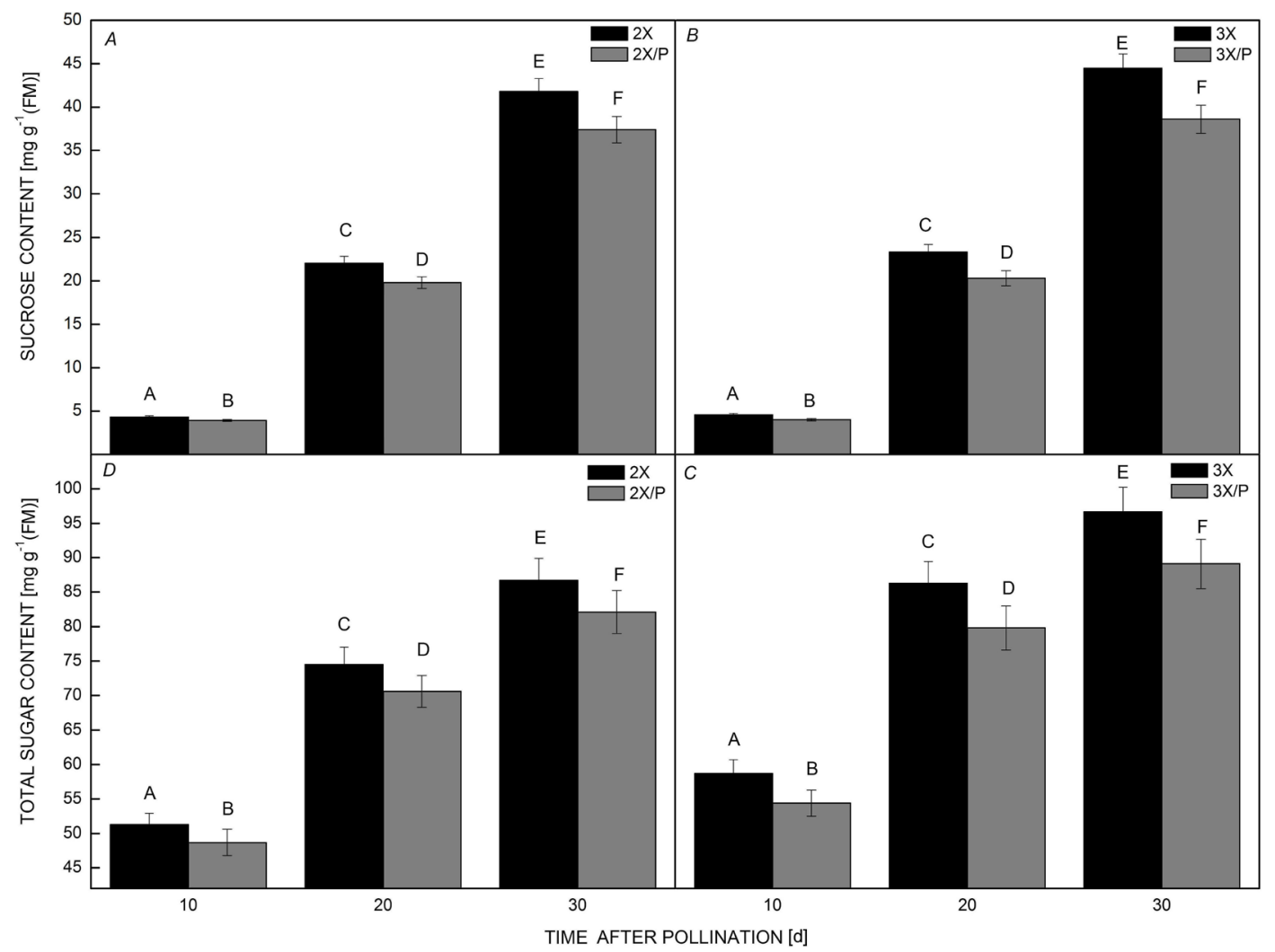

Fig. 7. Sucrose and total sugar accumulation in the flesh of grafted-root watermelon lines and own-root watermelon lines during the fruit development stage. Error bars show SE, $n=5$. One-way analysis of variance ( $A N O V A)$ was used to identify the difference between the grafted-root watermelon line and the corresponding own-root watermelon line in each treatment. Letters are comparable within graftedroot watermelon line and corresponding own-root watermelon line in each time. Values with different letters are significantly different $(P<0.05)$. 2X - diploid watermelon line, $3 \mathrm{X}$ - triploid watermelon line, $2 \mathrm{X} / \mathrm{P}$ - diploid watermelon line grafted onto pumpkin rootstock, $3 \mathrm{X} / \mathrm{P}$ - triploid watermelon line grafted onto pumpkin rootstock.

2016a). A vigorous pumpkin rootstock can increase dry mass and mineral concentration $(\mathrm{N}, \mathrm{K}, \mathrm{Ca}, \mathrm{Mg}$, etc.) in watermelon leaves (Huang et al. 2016a). Mineral nutrition is essential for plant growth and is involved in virtually all metabolic and cellular functions. For example, $\mathrm{Mg}$ is an essential macronutrient that is required for important functions related to ATPase activity, ATP biosynthesis, chlorophyll synthesis, $\mathrm{CO}_{2}$ assimilation, and phloem loading in leaves (Yang et al. 2012, Huang et al. 2016b). Leaves are the main photosynthetic organs, and the vigor of leaves and higher macronutrients concentration $(\mathrm{N}$, $\mathrm{K}, \mathrm{Mg}$, etc.) in leaves is beneficial for photosynthesis of pumpkin-grafted watermelon. Raffinose oligosaccharides are the main photoassimilates that are translocated in the phloem of Cucurbitaceae family members (Zhang et al. 2010). Alkaline $\alpha$-galactosidase is an important enzyme for raffinose oligosaccharides unloading and partitioning in cucumber and melon sink tissue (Pharr and Sox 1984, Gaudreault and Webb 1986, Gao and Schaffer 1999, Dai et al. 2011). Pumpkin rootstock improved alkaline $\alpha$-galactosidase activity in both the diploid and the triploid watermelon line (Fig. 4). More photoassimilates could be allocated to grafted-root watermelon fruit than to corresponding own-root watermelon fruit. Pumpkin rootstock could improve the synthesis of photoassimilates and their unloading into the fruit in both diploid and triploid watermelon. This may be the reason why pumpkin rootstock can increase fruit mass and dry matter content in both diploid and triploid watermelon.

Sucrose, glucose, and fructose are the main sugars in watermelon. Sucrose content increases rapidly over subsequent fruit developmental stage, while fructose and glucose contents remain almost constant during watermelon fruit development (Elmstrom and Davis 1981, Brown and Summers 1985, Kano 1991). Therefore, the difference in sugar content between watermelon cultivars is mainly determined by the sucrose content (Yativ et al. 2010). The sugar accumulation of crops depends on the ability of sink tissues to convert photoassimilates into sugar (Miralles and Slafer 2007, Reynolds et al. 2012, Tuncel and Okita 2013). The conversion capacity of photoassimilates to sucrose has become an important factor for sugar accumulation of watermelon fruit. The most wellstudied enzymes that function in sucrose metabolism during fruit development include three enzyme families, i.e., IAI, SuSy, and SPS. IAI is an extracellular enzyme that is bound to the cell wall (Karuppiah et al. 1989, Iwatsubo et al. 1992). Both phloem unloading and 
sucrose translocation to the developing sinks require IAI in sucrose-translocating plants (Godt and Roitsch 1997, Tang et al. 1999). SuSy is a key enzyme that catalyzes the synthesis of sucrose. A positive correlation between SuSy activity and sucrose accumulation was also reported in melon fruit (Burger and Schaffer 2007) and in watermelon (Yativ et al. 2010), suggesting that this enzyme plays an important role in determining sugar accumulation in sweet cucurbit fruit. SPS is another key enzyme that catalyzes sucrose synthesis. SPS is localized in the cytosol of the cells of many tissues including sink organs such as seeds and fruits (Huber and Huber 1996). SPS activity is positively related to sucrose accumulation in melon (Hubbard et al. 1989, Burger and Schaffer 2007) and watermelon (Yativ et al. 2010). In this experiment, although pumpkin rootstock increased $P_{\mathrm{N}}, \mathrm{ETR}, \mathrm{F}_{\mathrm{v}} / \mathrm{F}_{\mathrm{m}}$, $\Phi_{\text {PSII }}$, and alkaline $\alpha$-galactosidase activity, it decreased activities of IAI, SPS, and SuSy (Fig. 6). Previous studies have reported that physiological differences are strongly correlated with gene expression changes in the scion after grafting and some genes of the scion are upregulated or downregulated by rootstocks (Sun et al. 2020). In this study, the activities of IAI, SPS, and SuSy decreased in grafted watermelon lines $v s$. own-root watermelon lines. It remains possible that the genes encoding IAI, SPS, and SuSy in grafted watermelon lines were downregulated by pumpkin rootstock. The grafted plant always maintains the exchange of substances between scion and rootstock, for example, various types of plant RNA species move from cell to cell or systemically to potentially regulate grafted plant physiological processes (Lewsey et al. 2016, Huang et al. 2019). Pumpkins generally accumulate lower amounts of sugar in fruit than cultivated watermelon varieties. It could imply that some substances unfavorable to sugar synthesis from pumpkin rootstock move into watermelon scion, and inhibit expression of genes encoding IAI, SPS, and SuSy in the grafted watermelon lines. The lower activities of IAI, SPS, and SuSy would reduce the conversion of photoassimilates to sucrose in the grafted-root watermelon line. Sucrose accumulation was downregulated in the grafted-root line $v s$. corresponding own-root line in both diploid and triploid watermelon. As a result, sucrose and total sugar contents of the grafted-root line were lower than those of the corresponding own-root line in both diploid and triploid watermelon.

In conclusion, pumpkin rootstock increased $P_{\mathrm{N}}$, ETR, $\mathrm{F}_{\mathrm{v}} / \mathrm{F}_{\mathrm{m}}$, and $\Phi_{\mathrm{PSII}}$ during the fruit development stage in both the diploid watermelon line and the triploid watermelon line. These advantages could improve photosynthetic capacity, the utilization efficiency of light energy, and photosynthate assimilation in both the diploid and triploid watermelon lines. The activity of alkaline $\alpha$-galactosidase was much higher in the grafted-root watermelon line than that in the corresponding own-root watermelon line during fruit development, which accelerated photoassimilate unloading and partitioning in grafted-root watermelon fruit. It was the reason why the dry matter content and mass of grafted-root lines were higher than those of the corresponding own-root line in both diploid and triploid watermelon fruit. On the other hand, pumpkin rootstock decreased the activities of IAI, SPS, and SuSy during fruit development in both diploid and triploid watermelon flesh. The lower IAI, SPS, and SuSy activities were disadvantageous for converting photoassimilates into sucrose in the grafted-root watermelon lines, which caused that the sucrose and total sugar content in the flesh of the grafted-root line was lower than those in the flesh of corresponding own-root line regardless of diploid watermelon or triploid watermelon.

\section{References}

Albacete A., Martínez-Andújar C., Martínez-Pérez A. et al.: Unravelling rootstock $\times$ scion interactions to improve food security. - J. Exp. Bot. 66: 2211-2226, 2015.

Baker N.R.: Chlorophyll fluorescence: a probe of photosynthesis in vivo. - Annu. Rev. Plant Biol. 59: 89-113, 2008.

Brown A.C., Summers W.L.: Carbohydrate accumulation and color development in watermelon. - J. Am. Soc. Hortic. Sci. 110: 683-686, 1985.

Burger Y., Schaffer A.A.: The contribution of sucrose metabolism enzymes to sucrose accumulation in Cucumis melo. - J. Am. Soc. Hortic. Sci. 132: 704-712, 2007.

Chang H., Huang H.E., Cheng C.F. et al.: Constitutive expression of a plant ferredoxin-like protein (pflp) enhances capacity of photosynthetic carbon assimilation in rice (Oryza sativa). Transgenic Res. 26: 279-289, 2017.

Colla G., Rouphael Y., Cardarelli M. et al.: The effectiveness of grafting to improve alkalinity tolerance in watermelon. Environ. Exp. Bot. 68: 283-291, 2010.

Compton M.E., Gray D.J., Gaba V.P.: Use of tissue culture and biotechnology for the genetic improvement of watermelon. Plant Cell Tiss. Org. 77: 231-243, 2004.

Dai N., Cohen S., Portnoy V. et al.: Metabolism of soluble sugars in developing melon fruit: a global transcriptional view of the metabolic transition to sucrose accumulation. - Plant Mol. Biol. 76: 1-18, 2011.

Davis A.R., Perkins-Veazie P., Sakata Y. et al.: Cucurbit grafting.Crit. Rev. Plant Sci. 27: 50-74, 2008.

Elmstrom G.W., Davis P.L.: Sugars in developing and mature fruits of several watermelon cultivars. - J. Am. Soc. Hortic. Sci. 106: 330-333, 1981.

Gao Z., Schaffer A.A.: A novel alkaline $\alpha$-galactosidase from melon fruit with a substrate preference for raffinose. - Plant Physiol. 119: 979-988, 1999.

Garster H.: The potential role of lycopene for human health. J. Am. Coll. Nutr. 16: 109-126, 1997.

Gaudreault P.R., Webb J.A.: Alkaline $\alpha$-galactosidase activity and galactose metabolism in the family Cucurbitaceae. - Plant Sci. 45: 71-75, 1986.

Godt D.E., Roitsch T.: Regulation and tissue-specific distribution of mRNAs for three extracellular invertase isoenzymes of tomato suggests an important function in establishing and maintaining sink metabolism. - Plant Physiol. 115: 273-282, 1997.

Guo S., Zhang J., Sun H. et al.: The draft genome of watermelon (Citrullus lanatus) and resequencing of 20 diverse accessions. - Nat. Genet. 45: 51-58, 2012.

Hassell R.L., Memmott F., Liere D.G.: Grafting methods for watermelon production. - HortScience 43: 1677-1679, 2008.

Huang C., Wang Y., Yang Y. et al.: A susceptible scion reduces rootstock tolerance to Ralstonia solanacearum in grafted eggplant. - Horticulturae 5: 78, 2019.

Huang Y., Jiao Y.Y., Nawaz M.A. et al.: Improving magnesium uptake, photosynthesis and antioxidant enzyme activities of 
watermelon by grafting onto pumpkin rootstock under low magnesium. - Plant Soil 409: 229-246, 2016b.

Huang Y., Zhao L.Q., Kong Q.S. et al.: Comprehensive mineral nutrition analysis of watermelon grafted onto two different rootstocks. - Hortic. Plant J. 2: 105-113, 2016a.

Hubbard N.L., Huber S.C., Pharr D.M.: Sucrose phosphate synthase and acid invertase as determinants of sucrose concentration in developing muskmelon (Cucumis melo L.) fruits. - Plant Physiol. 91: 1527-1534, 1989.

Huber S.C., Huber L.H.: Role and regulation of sucrose phosphate synthase in higher plants. - Annu. Rev. Plant Phys. 47: 431-444, 1996.

Iwatsubo T., Nakagawa H., Ogura N. et al.: Acid invertase of melon fruit: immunochemical detection of acid invertases. Plant Cell Physiol. 33: 1127-1133, 1992.

Kalaji H.M., Bosa K., Govindjee et al.: Effects of salt stress on photosystem II efficiency and $\mathrm{CO}_{2}$ assimilation of two Syrian barley landraces. - Environ. Exp. Bot. 73: 64-72, 2011.

Kano Y.: Changes of sugar kind and its content in the fruit of watermelon during its development and after harvest. Environ. Control Biol. 29: 159-166, 1991.

Karuppiah N., Vadlamudi B., Kaufman P.B.: Purification and characterization of soluble (cytosolic) and bound (cell wall) isoforms of invertases in barley (Hordeum vulgare) elongating stem tissue. - Plant Physiol. 91: 993-998, 1989.

Kihara H.: Triploid watermelons. - Proc. Am. Soc. Hortic. Sci. 58: 217-230, 1951.

Lewsey M.G., Hardcastle T.J., Melnyk C.W. et al.: Mobile small RNAs regulate genome-wide DNA methylation. - P. Natl. Acad. Sci. USA 113: E801-E810, 2016.

Lin X., Zhang Y., Kuang H. et al.: Frequent loss of lineages and deficient duplications accounted for low copy number of disease resistance genes in Cucurbitaceae. - BMC Genomics 14: 335, 2013

Liu J., Guo S., He H. et al:: Dynamic characteristics of sugar accumulation and related enzyme activities in sweet and nonsweet watermelon fruits. - Acta Physiol. Plant. 35: 32133222, 2013.

Lowell C.A., Tomlinson P.T., Koch K.E.: Sucrose-metabolizing enzymes in transport tissues and adjacent sink structures in developing citrus fruit. - Plant Physiol. 90: 1394-1402, 1989.

Maroto J.V., Miguel A., Lopez-Galarza S. et al.: Parthenocarpic fruit set in triploid watermelon induced by CPPU and 2,4-D applications. - Plant Growth Regul. 45: 209-213, 2005.

Marr C.W., Gast K.L.B.: Reactions by consumers in a farmers' market to prices for seedless watermelon and ratings of eating quality. - HortTechnology 1: 105-106, 1991.

Miralles D.J., Slafer G.A.: Sink limitations to yield in wheat: how could it be reduced? - J. Agr. Sci-Cambridge 145: 139-150, 2007.

Miron D., Schaffer A.A.: Sucrose phosphate synthase, sucrose synthase, and invertase activities in developing fruit of Lycopersicon esculentum Mill. and the sucrose accumulating Lycopersicon hirsutum Humb. and Bonpl. - Plant Physiol. 95: 623-627, 1991.
Naumann J.C., Young D.R., Anderson J.E.: Linking leaf chlorophyll fluorescence properties to physiological responses for detection of salt and drought stress in coastal plant species. Physiol. Plant 131: 422-433, 2007.

Oukarroum A., Schansker G., Strasser R.J.: Drought stress effects on photosystem I content and photosystem II thermotolerance analyzed using Chl $a$ fluorescence kinetics in barley varieties differing in their drought tolerance. - Physiol. Plantarum 137: 188-199, 2009.

Oxborough K.: Imaging of chlorophyll a fluorescence: theoretical and practical aspects of an emerging technique for the monitoring of photosynthetic performance. - J. Exp. Bot. 55: 1195-1205, 2004.

Petropoulos S.A., Khah E.M., Passam H.C.: Evaluation of rootstocks for watermelon grafting with reference to plant development, yield and fruit quality. - Int. J. Plant Prod. 6: 481-492, 2012.

Pharr D.M., Sox H.N.: Changes in carbohydrate and enzyme levels during the sink to source transition of leaves of Cucumis sativus L., a stachyose translocator. - Plant Sci. Lett. 35: 187193, 1984.

Reynolds M., Foulkes J., Furbank R. et al.: Achieving yield gains in wheat. - Plant Cell Environ. 35: 1799-1823, 2012.

Shireen F., Nawaz M.A., Xiong M. et al.: Pumpkin rootstock improves the growth and development of watermelon by enhancing uptake and transport of boron and regulating the gene expression. - Plant Physiol. Bioch. 154: 204-218, 2020.

Shu S., Yuan L.Y., Guo S.R. et al.: Effects of exogenous spermine on chlorophyll fluorescence, antioxidant system and ultrastructure of chloroplasts in Cucumis sativus L. under salt stress. - Plant Physiol. Bioch. 63: 209-216, 2013.

Sun J.S., Hu R.Y., Lv F.L. et al.: Comparative transcriptome analysis reveals stem secondary growth of grafted Rosa rugosa 'Rosea' scion and $R$. multiflora 'Innermis' rootstock. Genes-Basel 11: 228, 2020.

Tang G.Q., Luscher M., Sturm A.: Antisense repression of vacuolar and cell wall invertase in transgenic carrot alters early plant development and sucrose partitioning. - Plant Cell 11: 177-189, 1999.

Tuncel A., Okita T.W.: Improving starch yield in cereals by over expression of ADPglucose pyrophosphorylase: Expectations and unanticipated outcomes. - Plant Sci. 211: 52-60, 2013.

Yang G.H., Yang L.T., Jiang H.X. et al.: Physiological impacts of magnesium-deficiency in citrus seedlings: photosynthesis, antioxidant system and carbohydrates. - Trees-Struct. Funct. 26: 1237-1250, 2012

Yativ M., Harary I., Wolf S.: Sucrose accumulation in watermelon fruits: genetic variation and biochemical analysis. - J. Plant Physiol. 167: 589-596, 2010.

Zhang B., Tolstikov V., Turnbull C. et al.: Divergent metabolome and proteome suggest functional independence of dual phloem transport systems in cucurbits. - P. Natl. Acad. Sci. USA 107: 13532-13537, 2010.

(C) The authors. This is an open access article distributed under the terms of the Creative Commons BY-NC-ND Licence. 